\title{
Tatlı Su Balıklarının Ichthyophthirius multifiliis Enfeksiyonunda Aşı Çalışmaları*
}

\author{
Coşkun Aydın', Gökmen Zafer Pekmezci² \\ ${ }^{1}$ Samsun Veteriner Kontrol Enstitüsü, Samsun \\ ${ }^{2}$ Ondokuz Mayls Üniversitesi Veteriner Fakültesi Su Ürünleri Hastalıklarl Anabilim Dalı, Samsun \\ Geliş Tarihi / Received: 12.04.2017, Kabul Tarihi / Accepted: 13.05.2017
}

\begin{abstract}
Özet: Tatlı su balıklarında çok tehlikeli olan "Beyaz Benek Hastalı̆̆ı" eski zamanlardan beri bilinmektedir. Hastalığın etkeni siliatalı bir protozoon olan Ichthyophthirius multifiliis' dir. Parazit doğal yaşam alanı ile kuluçkahane ve kafeslerde yetiştirilen her yaş ve boydaki tatlı su balıklarında enfeksiyona neden olur. Hastalığın Avrupa'da her yıl alabalık çiftliklerinde 140 milyon dolar zarara neden olduğu bilinmektedir. Ülkemizde hastalığın neden olduğu zararın ekonomik boyutunun ne olduğu tam olarak bilinmemektedir. Ama alabalık işletmelerin üretim potansiyellerine zarar verdiği bilinen bir gerçektir. Bu derlemede koruyucu hekimlik açısından I. multifiliis enfeksiyonlarında aşı yaklaşımları hakkında güncel veriler sunulmuştur.
\end{abstract}

Anahtar kelimeler: Ichthyophthirius multifiliis, İmmunite, Aş1

\section{Vaccination Studies on Ichthyophthirius multifiliis Infection in Freshwater Fishes}

\begin{abstract}
The "White Spot Disease" that is a very dangerous disease in freshwater fishes has been known since ancient times. Ichthyophthirius multifiliis is a ciliated protozoan. Parasite causes infection in freshwater fishes of all ages and sizes grown in habitats and hatcheries and cages. It is known that the disease is causing \$ 140 million loss in trout farms every year in Europe. It is not exactly known what the economic dimension of the harm is caused by the disease in Turkey. But, it is a fact that trout farms are damaging to their production potential. In this review, current vaccine approaches in I. multifiliis infections are presented in terms of preventive medicine.
\end{abstract}

Key words: Ichthyophthirius multifiliis, Immunity, Vaccine

\section{Giriş}

Tatlı su ekosisteminde yaşayan balıklarda çok tehlikeli bir hastalık olan Ichthyophthiriosis çok eski zamanlardan beri bilinmektedir. Hastalığın etkeni siliatalı protozoon olan Ichthyophthirius multifiliis'dir. Etken Oligohymenophorea sinıfinda ve Ichthyophthirius cinsinde yer alan tek türdür. Parazit doğal yaşam alanı ile kuluçkahane ve kafeslerde yetiştirilen her yaş ve boydaki tatlı su balıklarında enfeksiyona neden olur. Salgınlar sonucunda balıklardaki ölüm oranları \%100'lere ulaşabilmektedir. Parazit solungaç filamentleri, deri ve yüzgeçlerin epidermis tabakasına penetre olur. $\mathrm{Bu}$ tabakada derin olarak yerleşir ve oluşan beyaz renkli veziküllerin içerisinde gelişmesine devam eder. Enfeksiyonda deri, yüzgeç ve solungaçlarda $1 \mathrm{~mm}$ çapına ulaşan beyaz noktalar/benekler halinde veziküler lezyonlar görülmektedir. Karakteristik olan bu lezyonlar nedeni ile hastalık "Beyaz Benek Hastalığı" olarak isimlendirilir. Parazit kozmopolit bir türdür ve tüm dünyada yaygındır. Etken balık popülâsyonlarında çeşitli faktörlerin etkisi ile salgınlara ve sonuçta ölümlere neden olmaktadır. Salgınların olmadığı zamanlarda parazit, balık popülasyonlarında hafif enfeksiyon düzeyinde persiste halde beklemektedir. Kuluçkahane ve kafes sistemlerinde kalabalık barındırma, yoğun stoklama ve stres koşulları (düşük oksijen seviyesi, su sıcaklığı, suyun kimyasal kirliliği vb.) hastalığın seyrini olumsuz yönde etkileyip, enfeksiyonun hızlı bir şekilde yayılmasına ve salgınların ortaya çıkmasına neden olur. Enfeksiyonun ortaya çıkmasında ve salgınlar sonucu mortalitenin şekillenmesinde su sıcaklığı çok önemlidir. Parazitin yaşam döngüsü ile su sıcaklığı arasında yakın bir ilişki bulunmaktadır. Enfeksiyon genellikle su sıcaklığının artmasına bağlı olarak özellikle ilkbahar aylarında patlak verir

*Bu derleme birinci yazarın Yüksek Lisans seminerinden özetlenmiştir. Yazuşma adresi / Correspondence: Gökmen Zafer Pekmezci (ORCID: 0000-0002-7791-1959), Ondokuz Mayls Üniversitesi Veteriner Fakültesi Su Ürünleri Hastalıkları AD, Samsun, Türkiye 
$[17,18,24,26]$. Avrupa'da her yıl alabalık çiftliklerinde hastalık 140 milyon dolar zarara neden olmaktadır [16]. Ülkemizde hastalığın neden olduğu ekonomik zararın boyutunun ne olduğu bilinmemekle beraber işletmelerin üretim potansiyeline zarar verdiği bilinen bir gerçektir.

$\mathrm{Bu}$ derlemede koruyucu hekimlik açısından $I$. multifiliis enfeksiyonlarında aşı yaklaşımları hakkında güncel veriler sunulmuştur.

\section{İmmunite ve Antijenik Yapı}

Ichthyophthirius multifiliis enfeksiyonlarında mukozal immun yanıt ile sistemik antikor yanıtı ön plana çıkmaktadır. Parazite karşı immun sistemi uyarılmış Ictalurus punctatus, Cyprinus carpio ve Salmo gairdneri balıklarının serum ve mukusunda bulunan antiparazitik faktörler invitro koşullarda theront ve trofontları hareketsiz (immobilize) hale getirmiş ve aglitüne etmiştir. Bu immobilizasyon aktivitesinin parazite karşı gelişen spesifik antikorlara bağlı olduğu ve antikorların parazitin membran yüzeyinde bulunan silier antijenlerine bağlanarak therontların mukus tabakasına penetrasyonlarının engellendiğ $i$ görülmüştür. Hafif enfeksiyonlarda mukus immobilizasyon titresinin serum titresine göre fazla oldu$\breve{g u}$, hastalık semptomları kaybolduktan sonra serum titresinin $\operatorname{arttığ} 1$ ve bu artışın uzun bir süre yüksek kaldığ 1 bilinmektedir. Enfeksiyon sonrası balıklarda koruyucu immun yanıt gelişmekte ve bellek B lenfositler uzun süre humoral yanıtı aktif halde tutmaktadır. Bu durum enfeksiyona karşı koruyucu aşılamanın mümkün olduğunu göstermiş ve aşıların geliştirilmesi yönünde büyük çaba harcanmasına katkı sağlamıştır [2, 16-18].

Ichthyophthirius multifiliis'in tüm yüzeyi membran proteinleri ile kaplıdır. Bu proteinler immobilizan antijen (i-antijen) olarak ifade edilmektedir. Balıklarda oluşan immun yanıtın birinci derece hedefi bu i-antijenlerdir. I-antijenler doğal olarak enfekte balıklarda güçlü humoral yanıtın oluşmasını sağlar [5, 13, 17, 18, 22]. Ichthyophthirius multifiliis'in trofont, tomont ve enfektif theront evrelerinde farklı düzeylerde i-antijenleri eksprese ettikleri bilinmektedir [1]. Suşların serotipik olarak ayrımında, parazitin yüzey immobilizan antijenlerini hareketsiz kılan suşlara spesifik antiserumlar kullanılarak 5 farklı serotip (A, B, C, D, E) identifiye edilmiştir [9,
14, 15]. Bu serotipler arasında çapraz bağışıklığın gözlenmediği ve bağışıklığın sero-spesifik olduğu bilinmektedir [31]. G5 suşunun (serotip D) en yaygın suş olup, Çin'den ABD'ne kadar yaygın olduğu bildirilmiştir. G5 suşundan sonra, G1 suşunun (serotip A) en iyi şekilde moleküler olarak karakterize edildiği ve suşun sadece Georgia (ABD) ve New York (ABD) kökenli olduğu belirtilmiştir [16-18, 22]. Parazitin G5 ve G1 suşları haricinde ARS-6, G15, NY3, NY4, NY7, Ark5, Ark7, Ark9 ve Ark10 suşları da bilinmektedir. Bu suşların orijini Amerika Birleşik Devletleri'dir [16, 25, 35].

\section{Aşı Çalışmaları}

Parazite karşı korunmada etkili aşıların geliştirilmesinde i-antijenlerin kodladığ 1 proteinlerin farklılığ 1 son derecede önemlidir. Bu nedenle $I$. multifiliis'in farklı suşlarının i-antijen genlerinin moleküler karakterizasyonları ve klonlanma çalışmaları başarılı bir şekilde yapılmıştır $[12,16,22$, 35]. Ichthyophthirius multifiliis 'in i-antijenleri glycosyl-phosphatidyl-inositol (GPI) yapısındadir. I-antijenlerin SDS-PAGE ve Western Blots analizlerinde $\sim 37-60$ kilodalton $(\mathrm{kDa})$ arasında molekül ağırlığına sahip olduğu gözlenmiştir [8-11, 22, 35]. Parazitin i-antijenleri hastalıktan korunmak için potansiyel aşı adaylarıdır. G1 (serotip A) suşunun $\sim 48$ kDa, ARS-6 suşunun $~ 37$ kDa ve G5 (serotip D) suşunun $\sim 52 / 55 \mathrm{kDa}$ ağırlığında i-antijenlerini eksprese ettikleri çok net olarak kanıtlanmıştır [10, 11, $22,35]$. Bugüne kadar parazitin sadece en yaygın suşu olan ABD orijinli G5 suşu ile yine ABD orijinli G1 ve ARS-6 suşlarının i-antijenlerini kodlayan gen bölgeleri klonlanmış ve moleküler karakterizasyonları yapılarak Genbank veri kayıtları girilmiştir. Klonlanan izolatlarda i-antijenlerin ekspresyonu sabit kaldığ 1 için, bu antijenler I. multifiliis 'in serotiplerinin/suşlarının ayrımında da kullanılmaktadır $[10,11,14,22,35]$. Bu suşlardan G1'in $\sim 48$ $\mathrm{kDa}$ ağırlığındaki protein kodlayan i-antijen gen bölgesinin (IAG48[G1]) 1329 baz ve 442 aminoasit (aa) dizilimine sahip olduğu bilinmektedir [10]. G5 suşunun $\sim 52 / 55 \mathrm{kDa}$ ağırlığındaki i-antijenini eksprese eden iki farklı gen bölgesi (IAG52A[G5] ve IAG52B[G5]) karakterize edilmiştir. Genbank'a AF324424 erişim numarası ile kayıtlı olan protein kodlayan IAG52A[G5] gen bölgesi 1407 baz ve 468 aa dizilimine, AF405431 erişim numarası ile 
kayıtlı olan protein kodlayan IAG52B[G5] gen bölgesi 1383 baz ve 460 aa dizilimine sahiptir. Bu gen bölgelerinden 52B'nin 52A'ya göre 100 kat daha fazla transkripsiyon düzeyine sahip olduğu ispatlanmıştır [22]. Ayrıca ARS-6 suşunun Genbank'a FJ012354 erişim numarası ile kayıtlı olan $\sim 37 \mathrm{kDa}$ ağırlığındaki protein kodlayan i-antijen gen bölgesi 1358 baz ve 452 aa dizilimine sahiptir [35].

Ichthyophthirius multifiliis'in rekombinant proteinlerinin elde edilmesinde prokaryotik (bakteri) ve ökaryotik (Tetrahymena thermophila, memeli hücresi) hücre sistemlerinde protein ekspresyonlar1 yapılmıştır [6, 19]. Ichthyophthirius multifiliis non-standart genetik kodlara sahiptir [7]. Siliatalı protozoonların (I. multifiliis, Cryptocaryon irritans vb.) glutamin aminoasitini kodlayan UAA ve UGA kodonları, diğer organizmalar (bakteri, maya vb.) tarafından terminal (stop) kodon olarak algılanır. UAA ve UGA kodonları cDNA içinde TAA ve TGA olmak üzere üçlü nükleotid dizilimleri ile kodlanır. DNA mutasyon tekniği ile TAA ve TGA dizilimlerinin, E. coli gibi prokaryotik sistemlerde glutamin aminoasitini kodlanması için sırası ile CAA ve CAG nükleotid dizilimlerine modifiye edilmesi gerekir [21, 23, 28]. Ichthyophthirius multifiliis 'in dünyada en yaygın olduğu bilinen ABD orijinli G5 suşu tüm genomu sekanslanan ilk balık parazitidir. Bu genom çalışması sırasında G5 suşunda 17 adet yeni i-antijen geni identifiye edilmiştir. Bu antijenik determinantların karakterize edilmesi sonucunda yeni aşı proteinlerinin elde edilebileceğini bildirilmiştir [12].

Ichthyophthirius multifiliis'in immunojen olduğu ve spesifik bağışıklık oluştuğu bilinen bir gerçektir. Balıklarda immunizasyon denemelerinde canl1 theront, inaktive theront, canlı tomit, inaktive trofont ve sonike trofontlardan natif (doğal) olarak elde edilen antijenler deneysel olarak immersiyon ve intraperitonal yolla balıklara uygulanmış ve enfeksiyona karşı kısmi derecede koruma sağlanmıştır [3, 27, 29, 32-34]. Fakat parazitin antijenik determinantlarının gen düzeyinde moleküler olarak belirlenmesi koruyucu immun yanıt için hayati derecede önem arz etmektedir. Türkiye'de canlı theront, sonike trofont, 1s1 ile inaktive adjuvantlı theront aşılanan Gökkuşağı alabalıklarında I. multifiliis'e karşı oluşan humoral immun yanıt ve korunma düzeyleri araştırılmıştır. Araştırma sonucun- da doğal yolla elde edilen antijenler ile balıklarda kısmi korunma şekillendiği belirlenmiştir [27]. Bu aşı denemelerinde antijenlerin (theront, trofont $\mathrm{vb}$ ) elde edilmesinde canlı balıklar kullanılarak pasajlama yöntemlerine gidilmektedir. $\mathrm{Bu}$ nedenle işletmelerin üretim kapasiteleri dikkate alındığında antijenlerin hazırlanması ve inaktivasyonu için optimizasyonun sağlanmasının zor, zaman alıcı ve çok maliyet gerektirmesi nedeni ile ticari olarak lisans alması çok zordur. Bu nedenle rekombinant subunit aşıların, konvansiyonel antijenler ile hazırlanan aşılara göre daha fazla üstünlükleri vardır. Su ürünleri sektöründe hem bakteriyel hem de viral hastalıklara karş1 rekombinant proteinlerden ticari olarak üretilmiş ve sahada kullanılan rekombinant subunit aşılar bulunmaktadır $[4,16]$. Ichthyophthirius multifiliis'e karşı bu güne kadar herhangi bir ticari aşı üretilip ruhsat almamıştır, ancak hastalığa karşı ilk ticari aşının çok yüksek ihtimalle rekombinant protein aşısı olacağ 1 kanısı hâkimdir [16].

Rekombinant subunit protein aşılarıyla balıklarda immunizasyon çalışmaları yapılmıştır. İlk olarak G1 suşunun 442 aa dizilimine sahip $48 \mathrm{kDa}$ 'luk i-antijeninin sadece 316 bazlık küçük fragmentinin kodladığ1 105 aa içeren GST-füzyon protein bölgesi (repeat I) immunizasyon için hedef seçilmiştir [20]. Bu küçük gen bölgesi primerler ile çoğaltılmış ve sonrasında klonlanmıştır. Klonlanan gen bölgesinin kodon optimizasyonu yapıld1ktan sonra $E$. coli bazlı protein ekspresyon sisteminde başarılı şekilde rekombinant proteinleri elde edilmiştir. Elde edilen proteinler ile Carassius auratus'lar intraperitonal yolla immunize edilmiştir. Sonrasında immunize balıkların ölümcül dozda canlı parazitler ile çelinç enfeksiyonları yapılmıştır. İmmunize balıkların kontrol grubuna göre \%50' sinde yoğun enfeksiyon görülmesine rağmen, balıkların \%95 oranında hayatta kaldığ1 görülmüştür. Araştırıcılar elde edilen rekombinant proteinin I. multifiliis enfeksiyonlarına karşı potensiyel aşı olarak kullanılabileceği bildirmişlerdir [20]. Başka bir araştırmada, G5 suşunun $\sim 52 / 55 \mathrm{kDa}$ ağırlığ ındaki i-antijen proteini immunizasyon denemelerinde kullanılmıştır. G5 suşunun 1407 baz ve 468 aa içeren tüm gen bölgesi karakterize edildikten sonra rekombinant proteinleri bakteriyel ekspresyon sistemlerinde başarı bir şekilde elde edilmiştir. İntraperitonal yolla immunize edilen kanal yayın balıkları ölümcül dozda G5 therontla- 
n1 ile çelinç edildikten sonra, balıkların \%72'sinin hayatta kaldığ 1 görülmüştür. Araştırıcılar I. multifiliis'in i-antijenlerine karşı oluşan antikorların spesifik olduğunu ve akvaryum ile gida değeri olan balıkların bu rekombinant antijenler ile immunize edilerek aşılanabileceğini bildirmişlerdir [6]. Bu araştırmalar ile i-antijen geninin küçük bir fragmentinin kodladığ 1 protein ile tüm gen fragmentinin kodladığı proteinlerin balıklarda oluşturduğu koruma düzeylerinin farklı olduğu görülmektedir.

Oncorhynchus mykiss'lerde enfeksiyona karş1 DNA aşı (genetik immunizasyon) çalışmaları da yapılmıştır. DNA aşı çalışmaları ile yapılan en son güncel araştırmada 52A ve 52B i-antijen ile sistein proteaz gen bölgesi plazmid vektörlerine eksprese edilmiş ve immunizasyon için plazmidler balıklara uygulanmıştır. DNA immunizasyonu sonrasında balıklarda parazite karşı zayıf antikor yanıtı alınmış ve çelinç enfeksiyonlarına karşı korunma sağlanmamıştır. DNA immunizasyonunun korunma için yeterli mukozal antikor yanıtını uyaramadığı vurgulanmıştır [30].

Sonuç olarak I. multifiliiis'in kuluçkahane ve kafes sistemlerinde yetiştirilen Gökkuşağ 1 alabalıklarında salgın ve ölümlere neden olduğu bilinmektedir. Türkiye'de salgın ve ölümlere neden olan genotipler/genogruplar hakkında bugüne kadar herhangi bir araştırma yapılmamıştır. Bu yüzden Türkiye'de I. multifiliis saha suşlarının belirlenmesi gerekmektedir. Türkiye'de I. multifiliis 'in genotiplerine karş1 lisanslanmış herhangi bir aşı da yoktur. Bu nedenle Türkiye'de özellikle Gökkuşağ1 alabalığ sektöründe rekombinant subunit $I$. multifiliis aşısına gerek duyulmaktadir.

\section{Kaynaklar}

1. Abernaty J, Xu DH, Peatman E, Kucuktas H, Klesius P, Liu Z, (2011). Gene expression profiling of a fish parasite Ichthyophthirius multifiliis: Insights into development and senescence-associated avirulence. Comparative Biochemistry and Physiology Part D: Genom Proteomics. 6(4), 382-392.

2. Buchmann K, Sigh J, Nielsen CV, Dalgaard M, (2001). Host responses against the fish parasitizing ciliate Ichthyophthirius multifiliis. Vet Parasitol. 100(1), 105-116.

3. Burkart MA, Clark TG, Dickerson HW, (1990). Immunization of channel catfish, Ictalurus punctatus Rafinesque, against Ichthyophthirius multifiliis (Fouquet): Killed versus live vaccines. J Fish Dis. 13(5), 401-410.
4. Clark TG, Cassidy-Hanley D, (2005). Recombinant subunit vaccines: Potentials and constraints. Dev Biologicals. 121, 153-163.

5. Clark TG, Dickerson HW, Gratzek JB, Findly RC, (1987). In vitro response of Ichthyophthirius multifiliis to sera from immune channel catfish. J Fish Biol. 31, 203-208.

6. Clark TG, Dickerson, HW, Lin TL, (2006). Diagnostic and protective antigen gene sequences of Ichthyophthirius. U.S. Patent No. 7,026,156. Washington. DC: U.S. Patent and Trademark Office.

7. Clark TG, Forney J, (2003). Free-living and parasitic ciliates. Craig A, Sherf A, eds. Antigenic Variation. London. Academic Press (Elsevier Science Ltd.). p. 387-402.

8. Clark TG, Gao Y, Gaertig J, Wang X, Cheng G, (2001). The I-antigens of Ichthyophthirius multifiliis are GPI-anchored proteins. J Eukaryot Microbiol. 48(3), 332-337.

9. Clark TG, Lin T, Dickerson HW, (1995). Surface immobilization antigens of Ichthyophthirius multifiliis: Their role in protective immunity. Annu Rev Fish Dis. 5, 113-131.

10. Clark TG, Lin TL, Jackwood DA, Sherrill J, Lin Y, Dickerson HW, (1999). The gene for an abundant parasite coat protein predicts tandemly repetitive metal binding domains. Gene. 229(1), 91-100.

11. Clark TG, McGraw RA, Dickerson HW, (1992). Developmental expression of surface antigen genes in the parasitic ciliate Ichthyophthirius multifiliis. Proc Natl Acad Sci. 89(14), 6363-6367.

12. Coyne RS, Hannick L, Shanmugam D, Hostetler JB, Brami D, Joardar VS, Kumar U, Saier M, Wang Y, Cai H, Gu J, Mather MW, Vaidya AB, Wilkes DE, Rajagopalan V, Asai DJ, Pearson CG, Findly RC., Dickerson HW, Wu M, Martens C, Van de Peer Y, Roos DS, Cassidy-Hanley DM, Clark TG, (2011). Comparative genomics of the pathogenic ciliate Ichthyophthirius multifiliis, its free-living relatives and a host species provide insights into adoption of a parasitic lifestyle and prospects for disease control. Genome Biol. 12(10), R100.

13. Dickerson HW, Clark TG, Findly RC, (1989). Ichthyophthirius multifiliis has membrane-associated immobilization antigens. J Protozool. 36(2), 159-164.

14. Dickerson HW, Clark TG, Leff AA, (1993). Serotypic variation among isolates of Ichthyophthirius multifiliis based on immobilization. J Eukaryot Microbiol. 40(6), 816-820.

15. Dickerson HW, Clark TG, (1996). Immune response of fishes to ciliates. Annu Rev Fish Dis. 6, 107-120.

16. Dickerson HW, Findly RC, (2014). Immunity to Ichthyophthirius infections in fish: A synopsis. Dev Comp Immunol. 43(2), 290-299.

17. Dickerson HW, (2006). Ichthyophthirius multifiliis and Cryptocaryon irritans (phylum Ciliophora. Woo PTK. eds. Fish Diseases and Disorders. Vol. 1. Protozoan and Metazoan Infections. Second Edition. CAB International. Wallingford, UK. p. 116-153.

18. Dickerson HW, (2012). Ichthyophthirius multifiliis. Woo PTK, Buchmann K. eds. Fish Parasites Pathobiology and Protection. CABI. Wallingford, UK. p. 55-72. 
19. Gaertig J, Gao Y, Tishgarten T, Clark TG, Dickerson HW, (1999). Surface display of a parasite antigen in the ciliate Tetrahymena thermophila. Nature Biotechnol. 17, 462-465.

20. He J, Yin Z, Xu G, Gong Z, Lam TJ, Sin YM, (1997). Protection of goldfish against Ichthyophthirius multifiliis by immunization with a recombinant vaccine. Aquaculture. 158(1), 1-10.

21. Lin Q, Yang M, Huang Z, Ni W, Fu G, Guo G, Wang Z, Huang X, (2013). Cloning, expression and molecular characterization of a 14-3-3 gene from a parasitic ciliate, Cryptocaryon irritans. Vet Parasitol. 197(3), 427-435.

22. Lin Y, Lin TL, Wang CC, Wang X, Stieger K, Klopfleisch R, Clark TG, (2002). Variation in primary sequence and tandem repeat copy number among i-antigens of Ichthyophthirius multifiliis. Mol Biochem Parasitol. 120(1), 93-106.

23. Lokanathan Y, Mohd-Adnan A, Wan KL, Nathan, S, (2010). Transcriptome analysis of the Cryptocaryon irritans tomont stage identifies potential genes for the detection and control of cryptocaryonosis. BMC Genom, 11,76.

24. Lom J, Dyková I, (1992). Protozoan parasites of fishes. Elsevier Science Publishers.

25. MacColl E, Therkelsen MD, Sherpa T, Ellerbrock H, Johnston LA, Jariwala RH, Chang W, Gurtowski J, Schatz MC, Hossain MM, Cassidy-Hanley DM, Clark TG, Chang WJ, (2015). Molecular genetic diversity and characterization of conjugation genes in the fish parasite Ichthyophthirius multifiliis. Mol Phylogen Evol. 86, 1-7.

26. Matthews RA, (2005). Ichthyophthirius multifiliis fouquet and ichthyophthiriosis in freshwater teleosts. Adv Parasitol. 59, 159-241.

27. Nemli E, (2011). Gökkuşă̆ alabalıkların (Oncorhychus mykiss)'nda Ichthyophthirius multifiliis'e karşı bağışıklık kazandırlması üzerine denemeler. Doktora Tezi, Ege Üniversitesi Fen Bilimleri Enstitüsü, İzmir.

28. Priya TJ, Lin YH, Wang YC, Yang CS, Chang PS, Song YL, (2012). Codon changed immobilization antigen (iAg), a potent DNA vaccine in fish against Cryptocaryon irritans infection. Vaccine. 30(5), 893-903.

29. Sin YM, Ling KH, Lam TJ, (1994). Passive transfer of protective immunity against ichthyophthiriasis from vaccinated mother to fry in tilapias, Oreochromis aureus. Aquaculture. 120(3), 229-237.

30. von Gersdorff Jørgensen L, Sigh J, Kania PW, HoltenAndersen L, Buchmann K, Clark TG, Rasmussen JS, Jensen KE, Lorenzen N, (2012). Approaches towards DNA vaccination against a skin ciliate parasite in fish. PLoS ONE. 7(11), e48129.

31. Wang X, Clark TG, Noe J, Dickerson HW, (2002). Immunisation of channel catfish, Ictalurus punctatus, with Ichthyophthirius multifiliis immobilisation antigens elicits serotype-specific protection. Fish Shellfish Immunol. 13(5), 337-350.

32. Xu DH, Klesius PH, Shelby RA, (2004). Immune responses and host protection of channel catfish, Ictalurus punctatus (Rafinesque), against Ichthyophthirius multifiliis after immunization with live theronts and sonicated trophonts. J Fish Dis. 27(3), 135-141.

33. Xu DH, Klesius PH, Shoemaker CA, (2009a). Effect of immunization of channel catfish with inactivated trophonts on serum and cutaneous antibody titers and survival against Ichthyophthirius multifiliis. Fish Shellfish Immunol. 26(4), 614-618.

34. Xu DH, Klesius PH, Shoemaker CA, (2008). Protective immunity of Nile tilapia against Ichthyophthirius multifiliis post-immunization with live theronts and sonicated trophonts. Fish Shellfish Immunol. 25(1), 124-127.

35. $\mathrm{Xu} \mathrm{DH}$, Panangala VS, Van Santen VL, Dybvig K, Abernathy JW, Klesius PH, Liu Z, Russo R, (2009b). Molecular characteristics of an immobilization antigen gene of the fish-parasitic protozoan Ichthyophthirius multifiliis strain ARS-6. Aquaculture Res. 40(16), 1884-1892. 